\title{
WEIGHT AND STABILITY ASSESSMENT OF SINGLE LAYERS OF ORDERLY PLACED OR PITCHED NATURAL ROCK
}

\author{
Nisa Nurmohamed ${ }^{1}$, Gosse Jan Steendam² and Jentsje van der Meer ${ }^{2}$ \\ In the Netherlands a special type of dike protection exists: a single layer of pitched \\ natural rock. These rocks were pitched one by one and put together in such a way that \\ they form a single tightly packed, but porous layer. But how stable are they? Can they \\ resist a storm with a extreme high return period? And for the assessment of that, can we \\ estimate the weight of the rock in situ in a non-destructive way? First a method is given \\ to assess rock weight in situ by measuring three sizes. Then a minimum stability \\ function has been developed.
}

\section{INTRODUCTION}

In the Netherlands a special type of coastal protection exists: a single layer of pitched natural rock. They exist as protection of dikes against wave attack and have been built roughly between 1820 and 1910. These protections have survived hundreds of years without showing large damage. But how stable are they? Can they resist a storm with a return period of 10,000 years - the safety criterion in the Netherlands? The assessment of the actual stability of this kind of structures is the topic of this paper. The approach was the following:

- determination of what is a pitched layer of natural rock

- development method for weight assessment from block shape

- measurements in situ and analysis of data

- analysis of available research on stability of single layers of rock

- establishment of guideline for safety assessment

- check of guideline against proven strength in historical storms

\section{WHAT IS A PITCHED LAYER OF NATURAL ROCK?}

The rock, which was used for the first applications on dikes some 150 years ago, for a part was gathered from the north part of the country as the remains of the last ice age. This rock is partly more rounded than natural rock from a quarry. Some of the rocks are nicely rounded, others do not show any wear due to the travel from Norway to the Netherlands and look like fresh quarry rock.

Another part of the rocks, however, came at that time from quarries from Norway. The weight of the rock in the single layer pitched rock varies roughly from $50-500 \mathrm{~kg}$. These rocks were pitched one by one and put together in such a way that they form a single tightly packed, but porous layer. Very often the

\footnotetext{
${ }^{1}$ Directorate-General for Public Works and Water Management, POBox 5044, 2600 GA Delft, NL, s.nurmohamed@dww.rws.minvenw.nl

2 Infram, POBox 16, 8316 ZG Marknesse, NL, gosse.jan.steendam@infram.nl / jentsje.vandermeer@infram.nl
} 
longest dimension was placed perpendicular to the slope to increase stability. All rocks have contact with each other and "loose" rocks do hardly or not exist.
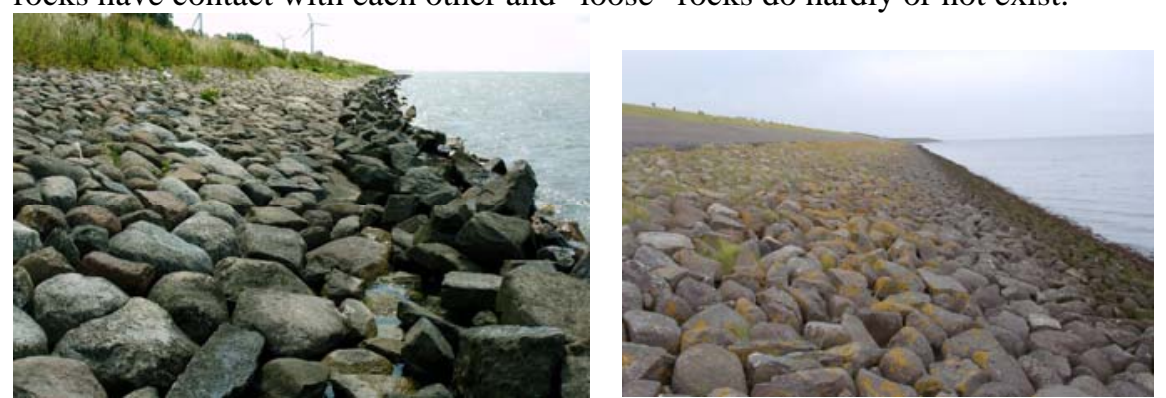

Figure 1. (left) Pitched rock slope along large lake with a randomly dumped rock berm in front and (right) Pitched rock slope along the Waddensea

Figure 1 gives an overall impression of these pitched natural rock slopes and The slope in the left picture of Figure 1 is situated along a large lake with a more or less constant water level. Around the water line a berm is present of loosely dumped quarried rock. The difference between randomly dumped and pitched rock is very clear. The right picture in Figure 1 gives a slope along the Waddensea, where tide and storm surge play a role.

\section{WEIGHT ASSESSMENT OF ROCK IN SITU FROM BLOCK SHAPE}

The blockiness coefficient developed by Stewart et al. (2003) appeared to be a valuable method to describe the weight of a rock by its shape. The blockiness coefficient $\mathrm{BL}_{\mathrm{c}}$ is defined as the ratio between the actual volume of a rock and the smallest rectangular box which fits the rock:

$$
\mathrm{BL}_{\mathrm{c}}=\mathrm{V}_{\text {rock }} /(\text { l.b.h })
$$

The values of $\mathrm{l}, \mathrm{b}$ and $\mathrm{h}$ can fairly easy be measured in situ. Also the mass density of the rock $\rho_{\mathrm{r}}$ is easy to measure in situ. If the blockiness coefficient, or shape factor, would be known for a certain rock, the mass $M$ would be known without weighing the rock itself:

$$
\mathrm{M}=\rho_{\mathrm{r}} \cdot \mathrm{BL}_{\mathrm{c}} \cdot \mathrm{l} \cdot \mathrm{b} \cdot \mathrm{h}
$$

This idea was developed further and the final method can also be used for other rock structures or breakwaters to get a good measure of the actual grading of the rock on a built structure. First of all small rock samples with different shapes were gathered. All these small rocks were ranked according to their measured $\mathrm{BL}_{\mathrm{c}}$-value and photographs of this ranking were made. Figure 2 shows a picture of all 25 rocks in a ranking. Other armour units for coastal protection were taken and also the blockiness coefficients of these units were measured, just for comparison with rock. Figure 3 gives an overall view.

The photograph in Figure 2 as well as photographs in which the rocks were arranged by certain blockiness ranges, were used to assess the actual blockiness coefficient in reality on a protection, for each rock measured in a batch. It should 
be noted that $\mathrm{BL}_{\mathrm{c}}=1$ is according to a cube and a value of 0.52 describes a sphere. It appears that nice blocky shapes have the highest coefficients around $\mathrm{BL}_{\mathrm{c}}=0.6-0.7$. Irregular shaped rock with triangular shapes have lowest values with $\mathrm{BL}_{\mathrm{c}}=0.3-0.4$. More rounded shapes come close to a ball or sphere with values around $\mathrm{BL}_{\mathrm{c}}=0.5$. The method was validated with natural rock in a stockpile. This method can be applied to normal rock protections if the rock size is not known.

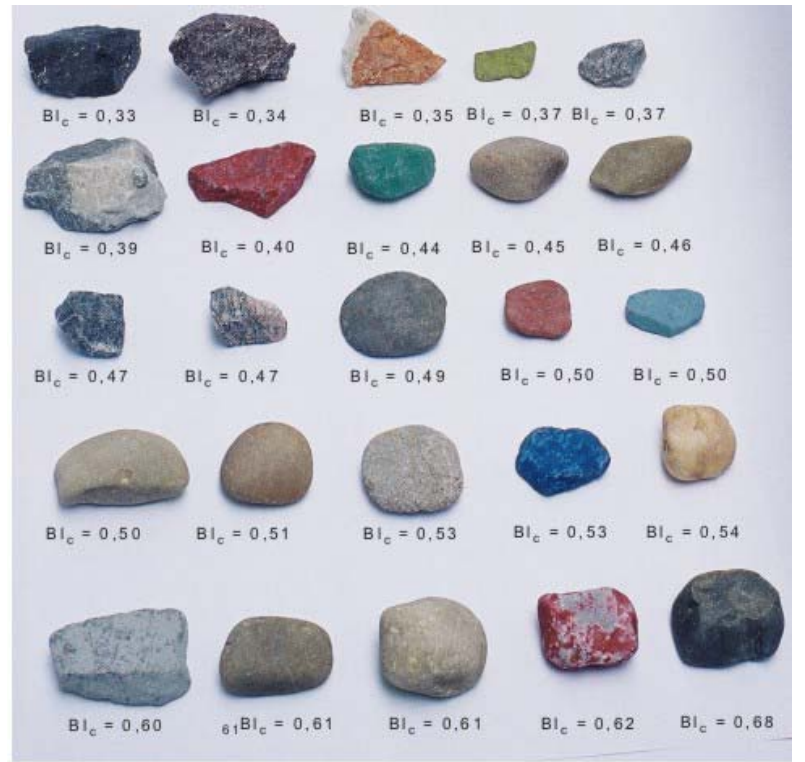

Figure 2. Different rock shapes ranked according to their blockiness coefficient BLc

Various locations with pitched natural rock were analyzed in detail. Every time the three dimensions of 10 rocks were measured. The weight of each rock was established based on the guessed blockiness coefficient of each rock. The ten rocks together give a (rough) grading curve as shown in Figure 4. In this figure the grading curves of all locations are given. Table 1 gives a summary of the findings, such as the average mass $M_{50}$, the nominal diameter $D_{n 50}$, the grading $D_{n 85} / D_{n 15}$ the layer thickness and the average blockiness coefficient. The average mass was not established by reading the value on the $50 \%$ line, but by estimating a straight line through the grading curve, matching the trend of the grading between the $15 \%$ and $85 \%$ lines. Therefore, values in Table 1 differ from direct readings from the graph.

The average mass of rock varies between 100-350 kg with corresponding nominal diameters of 0.35 to $0.50 \mathrm{~m}$. The grading of the rock is between 1.2 and 1.7 , which is a normal grading for quarried rock in coastal protections. The blockiness coefficients in average are about $\mathrm{BL}_{\mathrm{c}}=0.5$. 
It was decided that this value should be used for a safety assessment of pitched natural rock for all rocks and that 10 rocks should be measured (l, b and h) to establish the nominal diameter $\mathrm{D}_{\mathrm{n} 50}$.

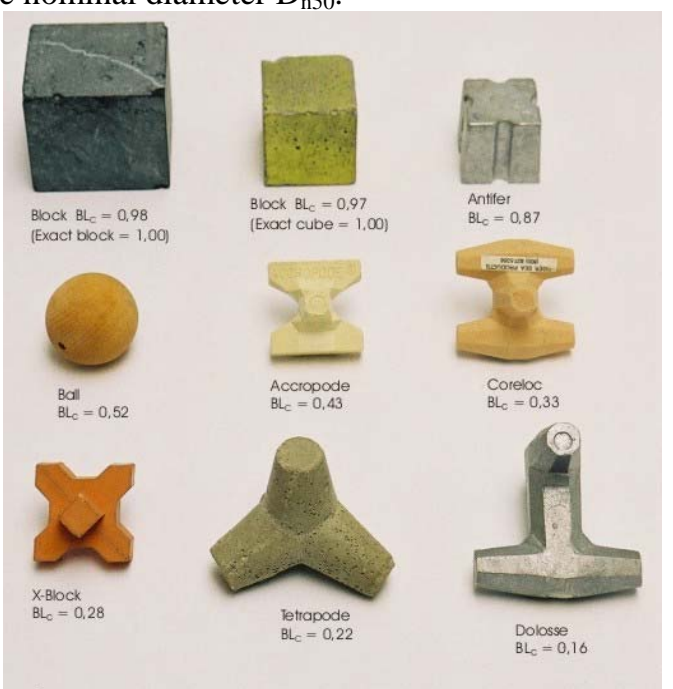

Figure 3. Blockiness coefficients for armour units

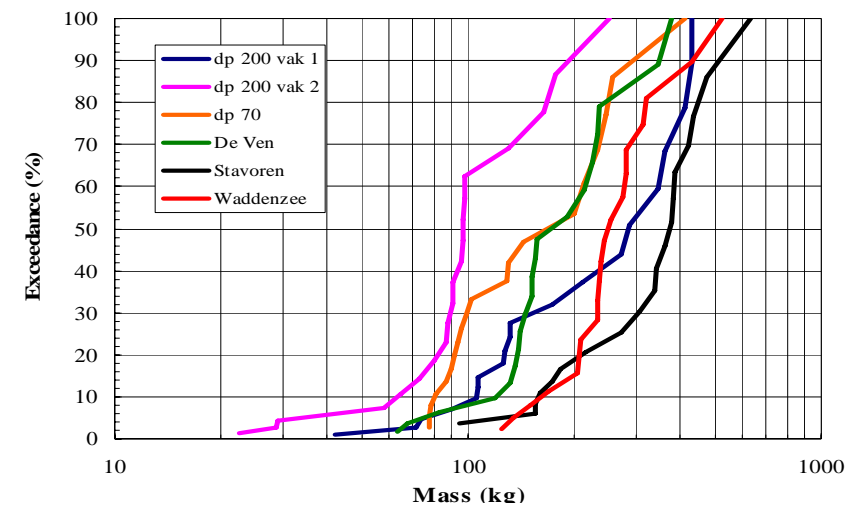

Figure 4. Grading curves for various pitched rock slopes, based on a non-destructive method to establish the weight of a rock

\begin{tabular}{|l|c|c|c|c|c|}
\hline \multicolumn{7}{|l|}{ Table 1. Measured rock grading at various locations } \\
\hline location & $\mathrm{M}_{50}$ & $\mathrm{D}_{\mathrm{n} 50}$ & $\mathrm{D}_{\mathrm{n} 85} / \mathrm{D}_{\mathrm{n} 10}$ & layer thickness & $\mathrm{BI}_{\mathrm{c}}$ \\
\hline & {$[\mathrm{kg}]$} & {$[\mathrm{m}]$} & {$[-]$} & {$[\mathrm{m}]$} & {$[-]$} \\
\hline $\mathrm{dp} 200$ vak 1 & 233 & 0,45 & 1,66 & 0,52 & 0,50 \\
\hline $\mathrm{dp} 200$ vak 2 & 107 & 0,34 & 1,26 & 0,41 & 0,50 \\
\hline dp 70 & 157 & 0,39 & 1,52 & 0,58 & 0,49 \\
\hline De Ven & 183 & 0,41 & 1,33 & 0,43 & 0,53 \\
\hline Stavoren & 348 & 0,51 & 1,29 & 0,51 & 0.57 \\
\hline Waddensea dike & 254 & 0,46 & 1,18 & 0,65 & 0,52 \\
\hline
\end{tabular}


STABILITY OF ORDERLY PLACED SINGLE LAYERS OF ROCK - A REVIEW

Stability of rock protections under wave attack can well be calculated by Van der Meer (1998), published in many guidelines. But those formulae concern only a two-diameter thick layer of randomly placed rock. The pitched natural rock slopes differ in two ways with these classical slope protections. First it is only a single layer and secondly this layer is not randomly placed, but pitched in a way to increase stability as much as possible. The formulae can only be regarded as a lower boundary condition.

Various researchers, however, have performed model tests on single layers of rock, where the rock was placed more carefully, but not pitched. Amongst them: Camfield (1996), Delft Hydraulics (1985), Hald (1998), Sollit and DeBok (1976), Stewart et al. (2003) and Van den Bosch (2001). It is clear that a randomly dumped single layer of rock is less stable than a two-diameters thick layer. This is, therefore, not the situation that should be regarded. If a single layer of rock is designed, more care should be taken to place the rock. It is not easy to describe what care exactly, but at least every stone should be placed individually and not dumped. The references given above all describe that the researchers have taken some care in placing their single layer of rock. The data from the research mentioned is described below and all together shown in Figure 5.

Stewart et al. (2003) performed an extensive research on packing densities, rock shape and the influence on stability and wave overtopping. A part of the research was focused on a single layer of rock.

The placing of rock was described as a "dense pack" where every rock was placed individually by crane. Tests were performed with different blockiness coefficients of the rock. Tests were performed with a permeable underlayer $(\mathrm{P}=0.5$, see Van der Meer (1988)) and with an impermeable underlayer $(\mathrm{P}=0.1)$.

The slope of the structure was $1: 2$. The tests with BLc $=50-60 \%$ and a permeable underlayer were repeated. These repetition tests showed lower stability. The results show "first damage". This could be one rock displaced or a few. Tests were stopped as soon as the first damage was observed.

Van den Bosch (2001) studied different placing patterns for a single layer of rock. Results in figure 5 are shown for the method were, if possible, rock was placed (but not pitched) with the longest axis perpendicular to the slope. Slopes of 1:2 and 1:3 were tested. Testing concerned only one wave steepness. Results are compared with a permeable underlayer. The results are just lower than the stability curves for classical rock layers, but the trend for plunging waves (lower stability for larger breaker parameter) is confirmed.

In Norway many breakwaters have been constructed with a single layer of large rock. These rocks were placed individually by a crane. Hald (1998) called this "orderly placed" and he performed tests for these steep slopes.

Sollit and DeBok (1976) performed large-scale tests in the flume of Oregon, USA. Tests were performed on approximately rectangular parallelepiped shaped rock and the longest axis was placed perpendicular to the slope. The slope was 
1:2 and the underlayer was permeable. Tests were performed with regular waves. A KD-factor of 29 was found for no “damage”. This gives $\mathrm{H} / \Delta \mathrm{Dn} 50=3.87$. If it is assumed that a regular wave height has similar effect as the $2 \%$-wave height in a random sea state, the stability factor can be calculated by dividing by 1.4 (being the ratio H2\%/Hs for relative deep water). This gives a stability factor of $\mathrm{Hs} / \triangle \mathrm{Dn} 50=2.76$. This value is also shown in Figure 5 for the range $\xi o p=2-3$.

In 1985 stability tests were performed in the Delta flume on small pitched natural rock (Delft Hydraulics, 1985). The fairly rounded rock (called Vilvoord rock) was placed with the longest axis perpendicular to the slope. The underlayer was fairly impermeable. With rock weighing in average $15 \mathrm{~kg}$ a significant wave height of 0.75 was withstood, giving $\mathrm{Hs} / \Delta \mathrm{Dn} 50=3.11$. The slope was $1: 3.5$, giving a small breaker parameter of $\xi o p=1.29$. Figure 5 gives this point with the corresponding curves for a classical structure. Stability is better for the tested structure.

Finally tests of Camfield (1996) will be described. He investigated orderly placed single layers of rock with regular waves. Direct stability results are not described in the paper. On request two not-published reports were received with stability results. Tests with an impermeable layer were described in Camfield and Reed (1998 - unpublished). Slopes of 1:1.5, 1:2 and 1:3 were investigated. Damage was defined as clear movement or as displacement of rock. With a clear movement the rock remained in the armour layer. As regular waves were used, a similar translation was made to random waves as for Solitt and DeBok (1976). The stability number was divided by 1.4 , keeping the same wave steepness.

In Camfield et al. (1999 - unpublished) tests were performed on a breakwater with a single layer of rock. The underlayer, therefore, can be considered as permeable. Again tests with regular waves were performed, but now a small 1:16 foreshore slope was present. Waves were only measured at deep water and sometimes had the same value as the water depth at the toe of the structure. As the wave height at the structure was not known, these tests were not further taken into account. Only two tests were performed with random waves. Although these results may also be less reliable, they are given in Figure 5. Both data points are located higher than the classical stability curves.

Two other references were found on stability of single layer of rocks, but both were not used. Bhageloe (1998) looked at a single layer of rock which was randomly dumped (as expected not very stable). McCartney and Ahrens (1976) looked at an overlay of small rock by one layer of large rock. Also here the placement of the single layer of rock was quite loose and stability was not high.

\section{ASSESSMENT OF STABILITY CURVE}

All stability results together for a single layer of orderly placed rock are given in Figure 5. Each point gives "initial damage”. The definition is not very sharp, it could be one or a few rocks displaced, but also first movement without displacement. Some structures were a kind of revetment with an impermeable 
core, others were more like a breakwater with permeable underlayers and core. Here all results are given together.

Stability of a randomly placed double layer of rock can be described by Van der Meer, 1988. This can be considered as the real lower boundary for orderly placed rock. The formula is given in Figure 5 for $\mathrm{S}=2$ and $\mathrm{S}=8$ for $\mathrm{P}=0.5$ (permeable underlayer) and for $\mathrm{S}=2$ and $\mathrm{P}=0.1$ (impermeable underlayer). Practically all model test results in Figure 5 are higher than the curve for an impermeable underlayer. Even many results are better than the curve for a permeable underlayer.

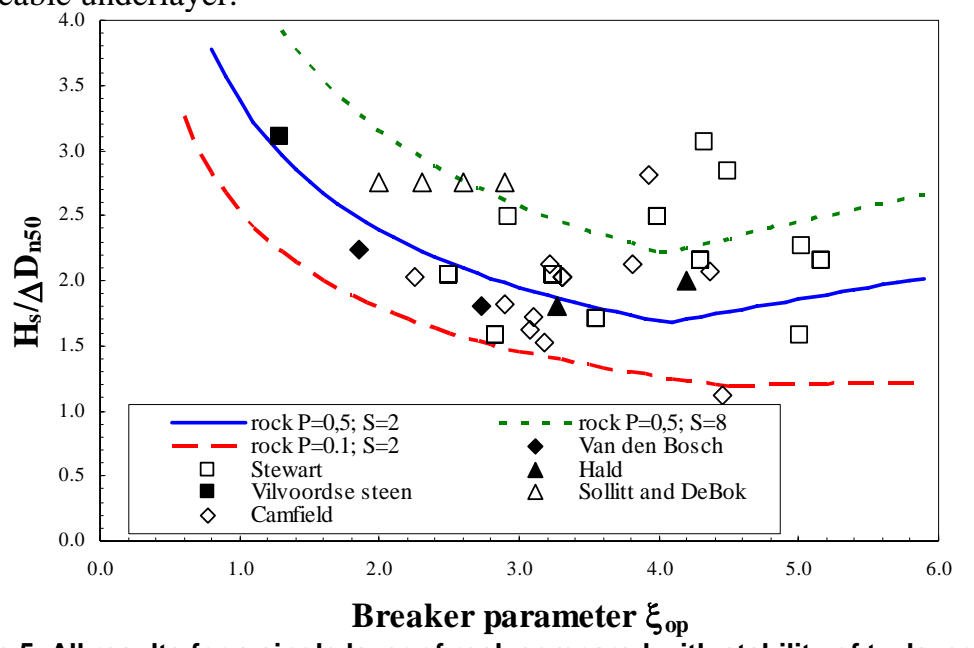

Figure 5. All results for a single layer of rock compared with stability of tw layers

Curves for a classical rock protection of two layers of randomly placed rock do not match with the total result of the single layer results, although the trend for plunging and surging waves seem to be present. This means lower stability for increasing breaker parameter for plunging waves and increasing stability for increasing breaker parameter for surging waves.

For single layers of rock we only want a curve for start of damage, as there is not enough data to describe damage development. It is, therefore, possible to develop a new formula for single layers of rock. And to be conservative, this curve should more or less describe the lower boundary of the data points. Figure 6 gives all data points again, but now with a new fit on this lower boundary. Except for two data points all other points are on or above this new fitted curve. In this figure all data with an impermeable underlayer are given by open symbols and data with a permeable underlayer are given by solid symbols. For the time being no distinction has been made between the two situations, although from theoretical point of view an impermeable underlayer should give a little lower stability.

The new fit in Figure 6 may be described by the following equations:

$$
\mathrm{H}_{\mathrm{s}} / \Delta \mathrm{D}_{\mathrm{n} 50}=4 \xi_{\text {op }}{ }^{-0.9} \text { for plunging or breaking waves (left in Figure 6) }
$$


$\mathrm{H}_{\mathrm{s}} / \Delta \mathrm{D}_{\mathrm{n} 50}=0,8 \xi_{\mathrm{op}}{ }^{0.6}$ for surging or non-breaking waves (right in Figure 6) (4)

The stability results of orderly placed rock in one layer may also be considered as a lower boundary for pitched rock in one layer. It is very likely that pitched rock is more stable than just orderly placed rock. Therefore, eq. 3 and 4 can also be considered as a lower boundary for the stability of pitched rock.

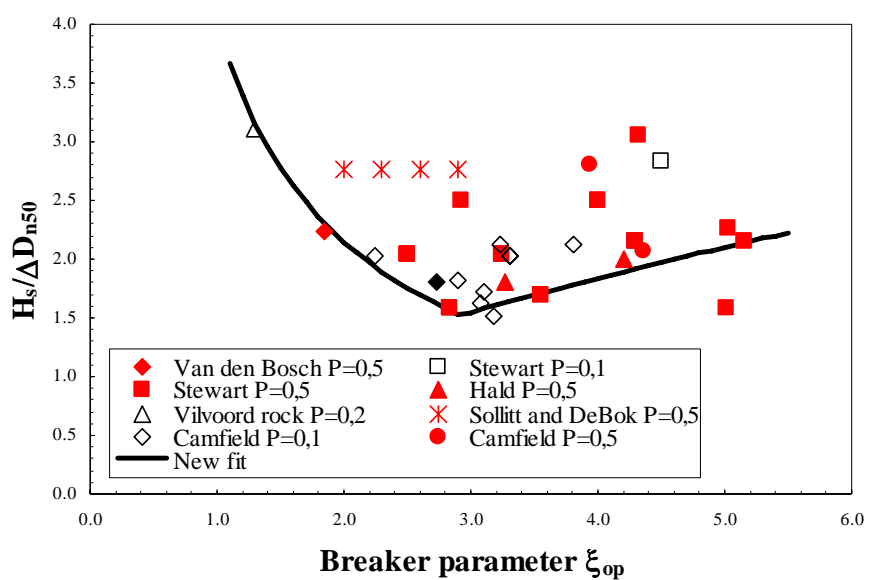

Figure 6. All results for a single layer of rock (solid symbols = permeable underlayer; open symbols=impermeable underlayer) compared with new fit as a lower boundary

\section{PROVEN STRENGTH FROM HISTORICAL STORMS}

Some structures with pitched rock exist already for a long time, without showing any damage. Damage due to storms has not been reported in the past 35 years. Also in the period before damage was not reported often, but there is not enough reliable data to go back further than about 35 years. Hindcasting some of the most severe storms for locations where there are relatively small pitched rock layers, may lead to stability numbers close to the new lower bounds as given by equations 3 and 4 . Part of the study on single layers of pitched rock concentrated on this "proven strength" method.

Two locations were chosen. First a location in one of the center lakes of the Netherlands was chosen. At this location south westerly storms do now give much higher wave conditions than in the past when the lake was still part of the Northsea, when the structure was constructed. The reason is the closure of the sea by two closure dams, creating two large lakes. As the wave attack was assumed quite low at time of construction, it was well possible that fairly small pitched rock was used here. The second location is along the Waddensea, where during a storm on 3 January 1976 a very severe storm moved, but not displaced, one pitched rock.

For the first location data was used which was available from earlier safety assessments. Average sizes of pitched rock were available and the geometry of the structure (mainly the slope of the protection). Severe storms were selected in 
the period after 1976 when one of the closure dams was constructed. For these storms the wave conditions at the location were hindcasted by using the measured wind velocity and direction and the measured water level. Six storms were selected and six cross-sections along the flood defence, giving a cloud of stabilitynumbers in Fig. 7. The berm in front of the slope was taken into account by a factor, as for wave run-up and overtopping, see Van der Meer (2002).

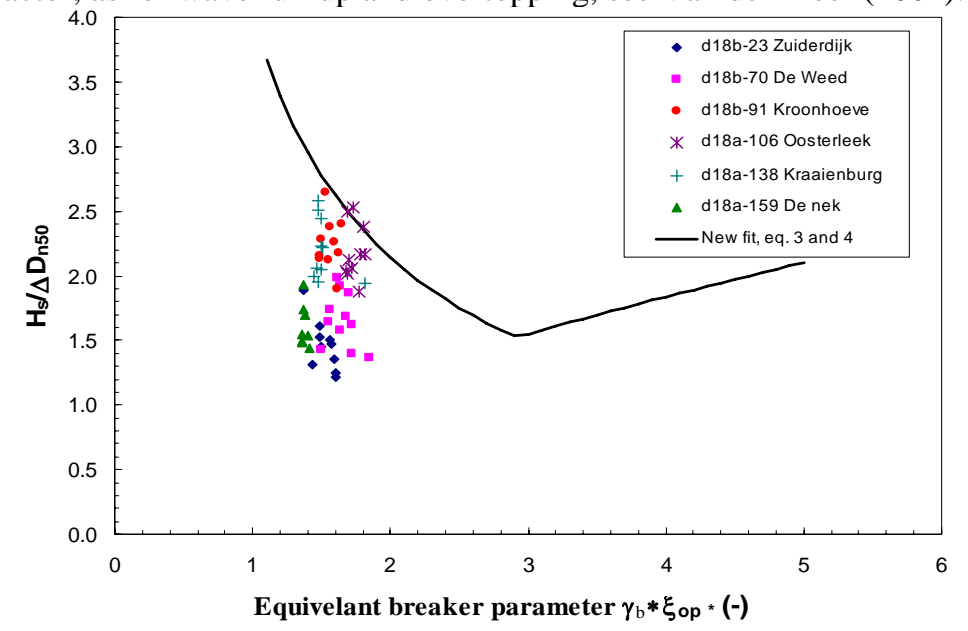

Figure 7. Hindcasted results for first location, based on limited data

This figure is very promising as some points are even on the new curve, where all data points can be considered as "no damage"! The problem, however, was that data was limited and based on conservative estimations in a safety assessment. This means that sizes were possible taken on the lower side and effect of a foreshore was ignored. For a first safety assessment this is a right procedure, but not for the method of proven strength. For the method of proven strength it should be proven that a certain wave heights has indeed occurred on the structure and that the average size of the rock is not taken too small. This is all just opposite to a safety assessment.

At all six locations the size of the pitched rock was measured and weight and grading was established according to the method described in this paper. It appeared that 5 of the 6 locations had larger rock on the slope than given in the safety assessment data. This clearly shows the conservatism in safety assessment, which is a common and good way, but these data can of course not be used as a good average of the situation.

The profiles of the dike sections, including the foreshore, were studied in depth. It appeared that in most cases a short foreshore was present, reducing the actual wave height at the structure. Thehindcasted wave heights were determined at about $200 \mathrm{~m}$ from the toe of the structure. This is more or less in "deep" water along the dikes of the lake as the average depth for the whole lake is around $4 \mathrm{~m}$ and long shallow foreshores do hardly exist. Due to this fairly shallow lake the 
wave heights during extreme storms are more or less depth limited. Fetch is not the governing parameter in this case, but water depth. It means also that any foreshore, even very short ones, will have influence on the wave height as the waves will directly start breaking.

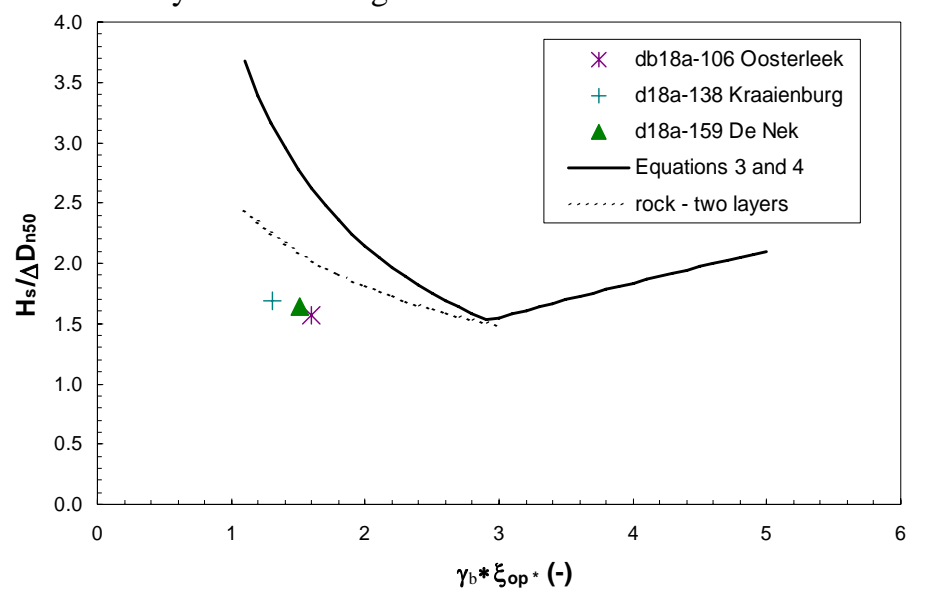

Figure 8. Hindcasted results for first location, based on detailed investigation

After the detailed investigation on the actual situation the same graph as in Figure 8 was constructed, but now with the real data. Only the largest storm was taken, giving the highest points close to the curve of Equation 3. Due to the larger rock than first assumed and the lower wave heights at the structure, the $\mathrm{H}_{\mathrm{s}} / \Delta \mathrm{D}_{\mathrm{n} 50}$-values reduced a lot. The data points are now even lower than the curve for start of damage for a classical two layers rock slope (Van der Meer, 1988).

The conclusion is that in this case the method of proven strength could not validate the assumption that equations 3 and 4 are a good estimation for start of damage of a single layer of pitched rock. The final conclusion on this exercise was that the approach of proven strength and the approach of a safety assessment are opposite to each other. For the method of proven strength one has to take into account all possible causes which may have led to lower wave conditions or a stronger structure than anticipated on limited data. One has really to prove that the structure has survived a given wave height.

Another location where the method of proven strength was applied, was along the Waddensea coast. The results are given in Figure 9. During storm surge the water level can raise $3-4 \mathrm{~m}$ and severe wave attack can be expected on the coastal protection. The storm on 3 January 1976 was a very severe one, which caused damage to revetments of some dike sections and which moved one rock in a single layer of pitched rock. The rock stayed within the layer, but moved to a position with the longitudinal axis perpendicular to the slope.

The highest water level was $3.7 \mathrm{~m}$ above mean sea level (the Dutch NAP), the wind velocity during at least 12 hours was around $21 \mathrm{~m} / \mathrm{s}$ and the wind 
direction was almost constant north west $320^{\circ}$. Wave heights at that time were not measured. But calculations on wave conditions in the Waddensea were performed in 1999 for fixed water levels, wind velocities and wind directions with the model SWAN. The results of these calculations could be used for the present study.

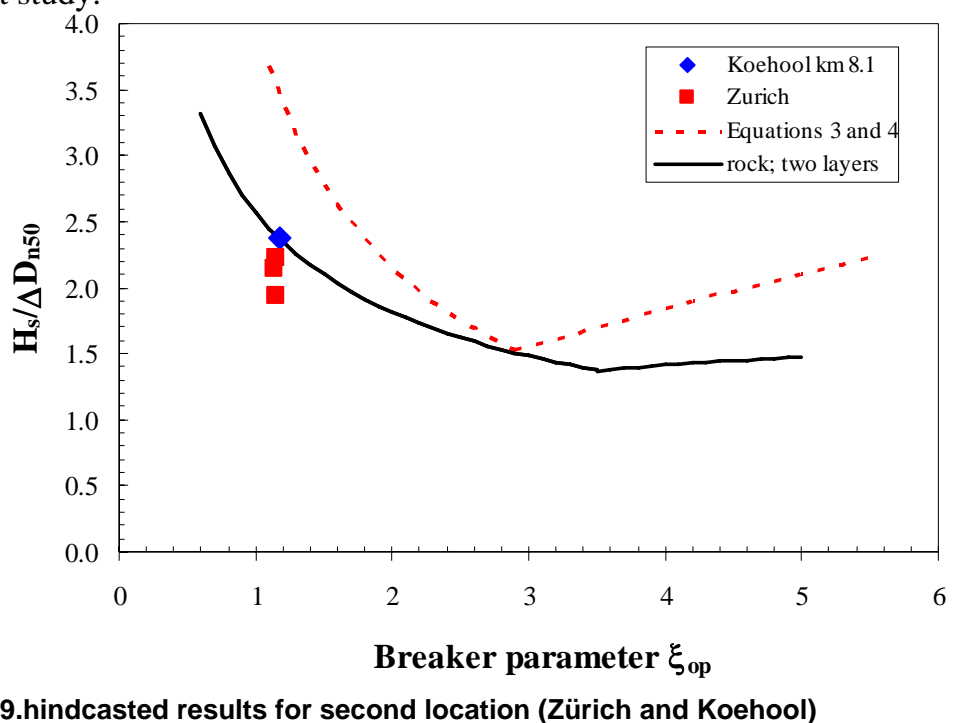

Figure 9.hindcasted results for second location (Zürich and Koehool)

Also the bottom topography was available. The bottom topography of the Waddensea has been measured since 1926 in a grid of $20 \mathrm{~m}$ by $20 \mathrm{~m}$. This bottom topography has changed drastically in some locations, mainly due to changes by mankind. For instance, the closure of the Zuiderzee by the Afsluitdijk, a $30 \mathrm{~km}$ long dike built in 1932 creating a fresh water lake, caused large changes along the coast in the vicinity of this dike. The effect of building such a dike influences the bottom topography for many years.

The calculations with SWAN were performed with the bottom topography available in 1999. The actual storm occurred in 1976 and the bottom topography has changed since then. Mainly the foreshore just in front of the dike raised by $1 \mathrm{~m}$ or even more.

Also here the actual rock size was determined with the method described in this paper. The results of the SWAN-calculations were used to establish the wave height at the toe of the structure. Finally the stability graph was drawn, which is given in Figure 9.

Two locations along the Waddensea dike were chosen, one at Zürich (where the rock was moved) and one at Koehool, about $20 \mathrm{~km}$ north. Figure 9 gives the results for 3 water levels for Zürich, including the peak of the storm and the highest water level at Koehool. The data points are close to the stability curve for the classical two layers of rock, but still do not validate equations 3 or 4 . 
The storm of 1976, however, was a very severe storm with gusts of 12 on Beaufort scale. It was felt that the hourly averaged wind velocity of $21 \mathrm{~m} / \mathrm{s}$ did not describe this situation in accurately. Moreover, in 1976 the foreshore was deeper than applied in the SWAN-calculations of 1999. Finally, based on the height level of debris on the dike and comparing this with run-up levels, only a higher wave height could have moved the debris to this level. For these reasons it was decided to investigate more in depth the hindcasted wave heights, with the expectation that the actual wave heights could increase for this location and this storm.

With information on the water depth in 1975 and new SWAN calculations with wind and water level conditions at the time of the storm, the actual wave heights at the locations were calculated. As a reference also the actual wave heights were derived with information on flood marks (debris) at the locations measured immediately after the storm.

Because of the local situation (no high foreshore) it was assumed that the flood mark gives the height of the maximum run up. With relations between maximum run up and $2 \%$ run up level (in this case Weibull distributed) the actual wave heights at the time of the storm could be derived. It was shown that the results with the Swan calculations were of the same order of magnitude than the results from hindcasting with measured flood levels. At one location the calculated actual wave height with SWAN had to be lowered a little for the comparison in $\mathrm{H}_{\mathrm{s}} / \Delta \mathrm{D}_{\mathrm{n} 50}-\xi_{\text {op }}$ plot as a result of the hindcasting with the measured flood levels.

The result of this study was that the points marked in figure 9 shifted up to above the stability relation of two layers of rock. It is therefore concluded that a single layer of pitched natural rock is at least as stable as two layers of randomly placed rock. Because the derived data points are still below the lines of equations 3 and 4 these equations could not yet be validated.

\section{CONCLUSIONS AND RECOMMENDATIONS}

A non-destructive method has been developed further to estimate the size of rock in a coastal protection in situ. This method can be used for all coastal structures consisting of rock. The blockiness coefficient $\mathrm{BL}_{\mathrm{c}}$ of Stewart et al. (2003) should be estimated for a batch of rocks in the protection by using Figure 2. A grading curve can then be established as the mass of each rock can be calculated by equation 2 .

A number of researchers have looked at the stability of orderly placed single layers of rock. Orderly placed means that attention has been paid to a way of constructing the slope in a more stable manor than only by random dumping. A single layer of orderly placed rock is more stable for "start of damage" than the randomly placed classical two layers of rock. Based on the combined result of various investigations from literature a lower bound was established for this kind of structures. It is assumed that a single layer of pitched rock is even more stable. The new stability formulae are given by equations 3 and 4 . 
The method of proven strength works opposite to a safety assessment. For a safety assessment one can start with conservative assumptions and a detailed study is only required if the structure is not strong or save enough under these conservative assumptions. For the method of proven strength one really has to prove that a certain wave condition has occurred and that the structure was modeled in the right way. The method of proven strength requires a detailed and in depth study from the start of the project.

Application of the method of proven strength did not yet give good enough data to validate equations 3 and 4 . It does not mean that the method is incorrect, but there are hardly locations where present design conditions with a return period in the order of $2500-10.000$ years have occurred.

\section{REFERENCES}

Bhageloe, G.S. 1998. Golfbrekers met een enkele toplaag. (In Dutch: Rubble mound structures with a single armour layer) MSc thesis TUDelft

Camfield, F.E. 1996. Natural periods of armor stones. Proc. ICCE 1996, ASCE, chapter 123.

Camfield, F.E. and R. Reed 1998. Selectively placed armor stone revetments. US Army Corps of Engineers, WES, Miscellaneous paper CHL-98-xx. Not published.

Camfield, F.E., D.L. Ward and R. Reed 1999. Single layer stability studies for revetments and breakwaters using selectively-placed armor stones. US Army Corps of Engineers, WES, Miscellaneous paper CHL-98. Not published.

Delft Hydraulics 1985. Sterkte Oosterscheldedijken onder geconcentreerde golfaanval. Onderzoek naar de stabiliteit van enkele veel voorkomende taludverdedigingen onder langdurige golfaanval bij vaste waterstand. Verslag grootschalig onderzoek. In Dutch.

Hald, T. 1998. Wave induced loading and stability of rubble mound breakwaters. PhD-thesis, Hydraulics \& Coastal Engineering Laboratory. Department of Civil Engineering, Aalborg, Denmark.

McCartney, B.L. and J.P. Ahrens 1976. Overlay of large, placed quarrystone and boulders to increase riprap stability. US Army Corps of Engineers, CERC, Technical paper No. 76-19.

Sollitt, C.K. and D.H. DeBok 1976. Large scale model tests of placed stone breakwaters. Proc. ICCE 1976, chapter 148. ASCE.

Stewart, T.P., S.D. Newsberry, J.-P. Latham and J.D. Simm 2003. Packing and voids for rock armour in breakwaters. HR Wallingford report SR 621.

Van den Bosch, A.F.M. 2001. Invloed van plaatsingsdichtheid op stabiliteit van "armour layers" van golfbrekers. MSc-thesis TUDelft, faculty of Civil Engineering.

Van der Meer, J.W. 1988. Rock slopes and gravel beaches under random wave attack. PhD-thesis, Delft University of Technology.

Van der Meer, J.W. 2002. Wave run-up and wave overtopping at dikes. TAW Technical report. 